\title{
PENGARUH MODEL PEMBELAJARAN CIRCUIT LEARNING DISERTAI LKPD TERHADAP HASIL BELAJAR FISIKA PESERTA DIDIK KELAS XI MIPA SMA KARTIKA I-5 PADANG
}

\author{
Mega Saventri, Husna, Helendra \\ Program Studi Pendidikan Fisika STKIP PGRI Sumatera Barat \\ Megasaventri17@gmail.com
}

\begin{abstract}
This study aims to determine whether there is an effect on the physics learning outcomes of students by applying the Circuit Learning model instead of using a scientific approach in class XI MIPA at SMA Kartika I-5 Padang. This type of research is a quasy experiment, with a randomized control group only design. This research was conducted in two sample classes, namely class XI MIPA 2 and class XI MIPA 4 at SMA Kartika I-5 Padang. The instruments used in this study were the essay test and the observation assessment sheet. Based on the results of data analysis, it was known that both sample classes were normally distributed and not homogeneous at the real level $=0.05$. The test statistic used was the two-parts t test. Based on the results of the calculation, hypothesis testing is obtained $=-7,25$ witht $_{\text {tabel }}=2,04$ because $-t_{\text {tabel }}<t^{1}<t_{\text {tabel }}$ with $=2.04$ because - then reject $\mathrm{H}_{0}$ and $\mathrm{H}_{1}$ is accepted where the hypothesis is accepted. Based on the results of the analysis, it can be seen that the experimental class activities are better than the control class learning activities. So it can be concluded that hypothesis in this study is physics learning. The outcomes learning of students using the Circuit Learning model accompanied by LKPD on students' physics learning outcomes were better than the physics learning outcomes of students who used scientific learning models in class XI MIPA SMA I-5 Kartika Padang.
\end{abstract}

\section{Keywords: Model Circuit Learning, Scientific}

\section{PENDAHULUAN}

Pendidikan merupakan langkah untuk menimba pengetahuan secara formal di lingkungan sekolah maupun informal di dalam rumah, di lingkungan masyarakat, bangsa dan negara. Sekolah merupakan tempat dimana sebagai lembaga pendidikan yang berperan penting dalam mencapai tujuan pendidikan nasional yaitu melewati proses pembelajaran. Banyak cara yang telah diterapkan oleh pemerintah untuk memperbaiki kualitas dan mutu pendidikan agar sesuai dengan tujuan pendidikan nasional diantaranya peningkatan dan penyempurnaan kurikulum 
pendidikan dari KTSP menjadi

Kurikulum 2013.

Kurikulum 2013 merupakan salah satu jawaban terhadap persaingan dan permasalahan perubahan dari abad ke-20 sampai abad ke-21. Kurikulum 2013 ini bertujuan untuk membentuk generasi yang harus memiliki kompetensi psikomotor, kompetensi kognitif dan afektif yang produktif, kreatif, inovatif dan afektif dalam pelaksanaan pembelajarannya.

Berdasarkan kurikulum 2013 diterapkan pendekatan saintifik dengan cara (amati, tanya, coba, nalar (komunikasi), Pada saat pembelajaran khususnya pembelajaran fisika.

Ilmu fisika merupakan suatu ilmu yang sangat penting oleh karena peserta didik diharapkan mampu untuk memahami konsep dan prinsip-prinsip dalam fisika, untuk memahami pembelajaran fisika itu sendiri peserta harus dilibatkan saat pembelajaran berlangsung, pendidik membuka peluang kepada peserta didik agar memperoleh pengetahuan melalui model pembelajaran aktif.
Menurut (Khairani, 2017 : 5) "Belajar adalah di mana proses mental yang mengarahkan pada penguasaan pengetahuan, kecakapan, skill, kebiasaan atau sikap yang semuanya di peroleh, di simpan dan dilakukan sehingga menimbulkan tingkah laku yang progresif dan adaptif. Sedangkan menurut (Karwono \& Mularsih, 2017:13) "Belajar yaitu adanya proses perubahan perilaku yang relatif permanen baik pengetahuan atau perilaku seseorang karena pengalaman".

Pemahaman konsep peserta didik dalam belajar materi fisika belum maksimal dan peserta didik banyak yang kurang dalam memahami konsep belajar fisika dengan benar. Seorang pendidik harus bisa menciptakan hal yang kreatif untuk menarik agar lebih mudah memahami konsep yang diberikan dan peserta didik lebih mempelajari untuk meningkatnya hasil belajarnya sehingga model yang baik digunakan untuk penelitian ini circuit learning di mana model ini menjadikan siswa aktif dan bisa 
menyelesaikan masalah dalam proses pembelajaran.

Menurut (Trianto, 2009 : 62) "Model pembelajaran berdasarkan masalah merupakan suatu model pembelajaran yang didasarkan pada banyaknya permasalahan yang membutuhkan penyelidikan autentik, yakni penyelidikan yang membutuhkan penyelesaian dari permasalahan yang nyata”. Misalnya gambar batang besi dipanaskan yang ditempelkan dipapan tulis sehingga peserta didik dapat menemukan dan menentukan apasaja yang terdapat pada batang besi dan peserta didik dapat menyimpulkan gambar yang telah peserta didik observasi sehingga permasalahan asli dapat diselesaikan dengan nyata sehingga dapat mendalami konsep bukan sekedar hafalan konsep atau rumus.

Pernyataan dari (Huda, 2013: 311) "Model Circuit learning dapat meningkatkan kreativitas peserta didik dalam merangkai kata dengan bahasasendiri dan melatih peserta didik untuk fokus pada gambar yang disajikan pendidik sehingga membuat pengetahuan peserta didik pada pembelajaran dialami sendiri oleh peserta didik menjadi bermakna dan sulit dilupakan”. Sedangkan menurut (Shoimin, 2016 : 34) "Circuit Learning adalah pembelajaran dengan memaksimalkan pemberdayaan pikiran dan perasaan dengan pola bertambah dan mengulang”.

\section{METODE PENELITIAN}

Terlaksanannya kegiatan ini pada semester satu tahun pelajaran 2019/2020 dikelas Sebelas MIPA SMA Kartika I-5 Padang pada tanggal 12 November sampai dengan 17 Desember 2019. Jenis Penelitian adalah kuasi eksperimen atau disebut juga dengan eksperimen semu, Penelitian adalah posttest only control design. Menurut (Arikunto, 2014 : 161) "Variabel adalah objek penelitian titik perhatian suatu penelitian".

Variabel bebas pada penelitian diperlakukan adalah model pembelajaran Circuit Learning dikelas eksperimen pendekatan pembelajaran saintifik kelas kontrol. Analisis soal yang tercantum dibawah ini : 
a. Indeks Kesukaran

$\mathrm{TK}=\frac{\text { Rata }- \text { rata }}{\text { Skor maksimum tiap soal }}$

Menurut (Arifin, 2016 : 135)

Berdasarkan indeks kesukaran soal sukar adalah pada rentang 0,00-0,30, pada rentang 0,31-0,70 soal sedang dan pada rentang $0,71-1,00$ soal mudah, apabila butir-butir item tersebut tidak terlalu sukar atau tidak terlalu mudah sehingga derajat kesukaran item termasuk kategori sedang, kriteria sedang pada soal 8 sedangkan pada soal 1,2,3,4,5,6,7 kriteria mudah.

b. Daya Pembeda

Menurut (Arikunto, 2016 : 133) daya pembeda soal adalah "kemampuan suatu soal untuk membedakan antara peserta didik yang pandai menguasai materi dengan peserta didik yang kurang pandai dalam memahami materi”. pada ketetapan daya pembeda dengan persamaan dibawah ini :

$$
D B=\frac{\bar{X} K A-\bar{X} K B}{\text { skor maksimum soal }}
$$

Berdasarkan daya pembeda soal kriteria dari 0,30-040 adalah kategori baik untuk soal yang dicobakan ada beberapa soal yang dipakai no 1,2,4,6 dan 8 sedangkan untuk soal 5 dan 7 harus di buang dikarenakan kurang dari kriteria.

c. Reliabilitas

Menurut Arikunto, (2014 : 239) "Reliabilitas merupakan ketetapan suatu tes apabila diteskan kepada subjek yang sama. Menentukan reliabilitas tes digunakan rumus dibawah ini yaitu".

$$
r_{11}=\left(\frac{n}{n-1}\right)\left(1-\frac{\sum \sigma_{i}^{2}}{\sigma_{t}{ }^{2}}\right)
$$

di mana $\quad \sigma_{t}^{2}=\frac{\sum x_{i}{ }^{2}-\frac{\left(\sum x_{i}\right)^{2}}{N}}{N}$

Berdasarkan perhitungan yang diperoleh bahwa didapat $r_{11}=$ $0,836 r_{\text {tabel }}=0,423$ Jadi dapat disimpulkan bahwa soal reliabel. Di mana instrumen berupa essay yang dujikan kepada peserta didik dan teknik pengumpulan data terdiri dari tahap persiapan berikut yaitu dalam mempersiapkan cara pelaksanaan penelitian.

Model pembelajaran Circuit Learning kedua kelas sampel dapat memiliki pendekatan saintifik dan tahap akhirnya berupa tes akhir yang diberikan. Tahap untuk selanjutnya hipotesis dalam mengetahui apakah hipotesis saat penelitian ini terbukti atau tidaknya. Tetapi sebelum menghitung hipotesis maka dicari 
terlebih dahulu normalitas dan homogenitas, sebagai berikut :

1. Normalitas

Berdasarkan penelitian yang telah dilaksanakan Uji yang digunakan adalah uji Lilliefors dengan menentukan nilai tertinggi dari $\left|F\left(z_{i}\right)-s\left(z_{i}\right)\right|$, hasilnya disebut L0. Kemudian bandingkan dengan $L_{\text {tabel }}$ kriteria pengujiannya adalah terima $\mathrm{H}_{0}$ jika $\mathrm{L}_{0}<L_{\text {tabel }}$, dalam hal lain $\mathrm{H}_{0}$ ditolak. penelitian yang sudah dilaksanakan pada kelas eksperimen diperoleh $L_{0}=0,0927$ dan $L_{t}=0,1590$ di mana $L_{0}<L_{t}$ maka sampel terdistribusi normal. Sedangkan kelas kontrol diperoleh $L_{0}=0,1248$ dan $L_{t}=0,1590$ di mana $L_{0}<L_{t}$ maka contoh terdistribusi normal.

\section{Homogenitas}

Menurut Sudjana, (2005:249) "Uji homogenitas bertujuan untuk menyelidiki apakah kedua sampel mempunyai variansi yang homogen atau tidak. Untuk mengujinya digunakan uji kesamaan dua variansi uji $F$ ”. Rumus yang digunakan :

$$
F=\frac{S_{1}{ }^{2}}{S_{2}{ }^{2}}
$$

Kriteria pengujiannya tolak $H_{0}$ jika $F \geq F_{\alpha(n 1-1, n 2-1)}$ dalam hal lain terima $H_{0} \quad$.Berdasarkan pengolahan data yang didapat, maka $F_{\text {hitung }}=1,1744$ dan $F_{\text {tabel }}=1,8752$, di mana kriteria pengujian $F_{\text {hitung }}<$ $F_{\alpha(n 1-1, n 2-1)}$ maka itu disimpulkan dua lokal memiliki variansi yang tidak homogen.

\section{Hipotesis}

Menurut (Sudjana, 2005 : 239) "Untuk data hasil belajar kedua kelas sampel terdistribusi normal dan mempunyai variansi tidak homogen, maka uji statistik yang di gunakan adalah".

$$
\begin{aligned}
t^{1} & =\frac{\overline{x_{1}}-\overline{x_{2}}}{\sqrt{\frac{s_{1}{ }^{2}}{n_{1}}+\frac{s_{2}{ }^{2}}{n_{2}}} \text { dengan }} \\
s^{2} & =\frac{\left(n_{1}-1\right) s_{1}{ }^{2}+\left(n_{2}-1\right) s_{2}{ }^{2}}{n_{1}+n_{2}-2}
\end{aligned}
$$

Kriteria pengujian adalah terima $H_{0}$ jika $-t_{1} 1-\frac{1}{2} \alpha<t^{1}<t_{1} 1-$ $\frac{1}{2} \alpha$ di mana $\mathrm{t}_{1} \frac{1}{2} \alpha t_{1-\alpha}$ diperoleh distribusi t dengan $\mathrm{dk}=\left(n_{1}+n_{2}-2\right)$ serta peluang $\left(1-\frac{1}{2} \alpha\right)$.Berdasarkan uji hipotesis yang dilakukan sehingga didapat $t_{\text {hitung }}=-7,25$ dan $t_{\text {tabel }}=2,04$.Karena $t_{\text {hitung }}<$ $t_{\text {tabel }}$ sehingga ditolak $H_{0}$ dan $H_{1}$ diterima.

Jadi disimpulkan pengaruh hasil belajar fisika penggunaan model 
pembelajaran circuit learning disertai LKPD dibandingkan dengan menggunakan pendekatan pembelajaran saintifik.

\section{HASIL DAN PEMBAHASAN}

Pada lokal eksperimen memakai model circuit learning di mana setiap kelompok diberikan LKPD diskusikan sebuah masalah yang ada dalam lembar tersebut dan di presentasikan semua anggota dengan cara bergantian ke depan, selanjutnya jika jawabannya benar maka mendapatkan pujian atau reward dari pendidik dan semua peserta didik dalam kelas tersebut.

Menurut (Huda, 2013 : 311) "Model Circuit learning dapat meningkatkan kreativitas peserta didik dalam merangkai kata dengan bahasa sendiri dan melatih peserta didik untuk fokus pada gambar yang disajikan pendidik sehingga membuat pengetahuan peserta didik pada pembelajaran dialami sendiri oleh peserta didik menjadi bermakna dan sulit dilupakan”. Setelah dilakukan penelitian, maka didapatkan hasil data tes akhir.
Tabel 1 Hasil data Tes Akhir

\begin{tabular}{ccccc}
\hline kelas & $\mathrm{N}$ & $x$ & $\mathrm{~S}$ & $\mathrm{~S}^{2}$ \\
\hline eksperimen & 30 & 71,39 & 9,10 & 82,88 \\
kontrol & 30 & 48,04 & 15,09 & 227,7 \\
\hline
\end{tabular}

Pada tabel bisa dilihat lokal eksperimen yang mempunyai jumlah peserta didik 30 orang didapatkan rata-ratanya yaitu 71,39 dengan simpangan bakunya yaitu 9,104 serta variansi sebesar 82,8, untuk local kontrol didapatkan ratanya 48,04 dengan simpangan bakunya yaitu 15,09 dan variansi sebesar 227,7 sehingga dapat dilihat dari tabel diatas pada tes akhir yang lebih baik kelas eksperimen dari pada kelas kontrol.

Nilai fisika lokal eksperimen lebih meningkat dari lokal kontrol, Untuk ranah afektif juga lokal eksperimen lebih tinggi dari lokal kontrol saat proses belajar berlangsung nilai diperoleh dari lembar observasi. Untuk mengetahui apakah hipotesis dalam penelitian ini diterima apakah ditolak, maka dilakukanlah tes normalitas dan homogen yang sudah kerjakan sebelumnya. 
Tabel 2 Uji Normalitas Kognitif

\begin{tabular}{cccccc}
\hline Kelas & Murid & $\mathrm{L}_{\text {hit }}$ & $\mathrm{L}_{\text {tabel }}$ & Distri \\
\hline Eksperimen & 30 & 0,0927 & 0,1614 & Normal \\
Kontrol & 30 & 0,1248 & 0,1590 & Normal
\end{tabular}

Hasil tabel 2 dapat dilihat pada kelas eksperimen dan kontrol samasama mempunyai 30 peserta didik perkelas yang di mana Lhitung lebih kecil dari Ltabel sehingga terdistribusi normal untuk kelas kontrol pun Lhitung Lebih kecil dari Ltabel sehingga terdistribusi normal, demikian $\mathrm{H}_{0}<\mathrm{H}_{1}$ tarafnya yaitu 0,05 maka kelas sampel berdistribusi normal dan didapatkan $F_{\text {hitung }}=2,75$ $F_{\text {tabel }}(0,05)(29,29)=1,86$ hal ini berarti data kedua kelas sampel yaitu hasil perhitungannya $F_{\text {hitung }}=2,75$ dan $F_{\text {tabel }}=1,86$ karena $t_{\text {hitung }}>t_{\text {tabel }}$ maka terima $\mathrm{H}_{1}$. Jadi kesimpulan dalam penelitian ini yaitu hipotesis di terima di mana hasil akhir dalam mengikuti pembelajaran dengan model circuit learning menggunakan LKPD berpengaruh terhadap hasil belajar peserta didik dari pada hasil belajar menggunakan pendekatan saintifik dikelas XI MIPA SMA Kartika I-5 Padang.
Penelitian yang sejalan dengan penelitian dicobakan oleh Ramadhani (2018) dengan judul "Penerapan Model Pembelajaran Circuit Learning Terhadap Kemampuan Komunikasi Matematis Siswa Kelas X SMA N 1 Pasir Penyu". Adapun penelitiannya bisa mengetahui kemampuan komunikasi matematis memakai model pembelajaran Circuit Learning. Hasil tersebut menyatakan kemampuan komunikasi matematis pada model belajar Circuit Learning lebih baik dari pada belajar konvensional. Penilaian sikap yang telah dinilai dalam proses belajar mengajar selama penelitian, yang telah tertulis dalam rata-rata kegiatan pada kelas sampel:

\begin{tabular}{ccc}
\multicolumn{3}{c}{ Tabel 3 Hasil Observasi Sampel } \\
\hline Pertemuan & Eksperimen & Kontrol \\
\hline 1 & 46,66 & 54,66 \\
2 & 47,99 & 51,99 \\
3 & 73,32 & 45,99 \\
Rata-rata & 55,96 & 50,88 \\
\hline
\end{tabular}

Berdasarkan tabel 3 bahwa rata-rata aktivitas peserta didik kelas sampel mengalami penurunan yang mana untuk kelas eksperimen terkategori cukup dan 
kelas kontrol kurang, ranah yang dinilai pada penelitian ini adalah afektif terdiri dari 5 indikator, hasil kegiatan pada kelas eksperimen sedikit lebih baik naik nilainya dari kelas kontrol kurang, dari pertemuan jumpa pertama sampai pertemuan jumpa ketiga tingkat aktivitas peserta didik kelas percobaan sedikit lebih tinggi dari kelas kontrol .bisa dilihat pada grafik dibawah ini :

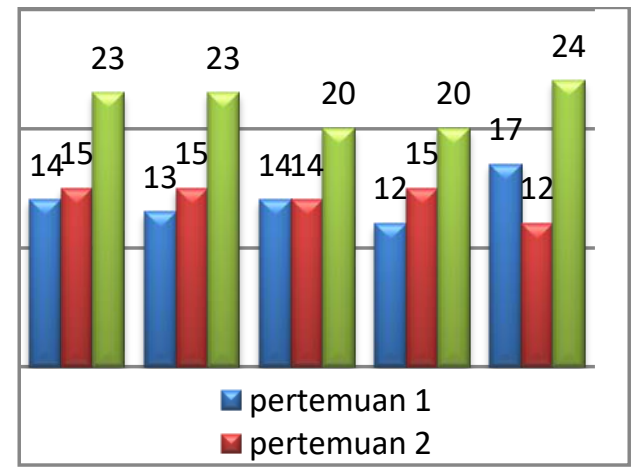

Gambar 1. Rata-Rata Aktivitas Peserta Didik Kelas Sampel

Berdasarkan gambar 1 dilihat rata-rata aktifitas dari peserta didikn kelas eksperimen dan kontrol dapat disimpulkan dalam proses pembelajaran berlangsung aktivitas yang lebih aktif kelas eksperimen dari pada kelas kontrol. Pada proses kelas eksperimen menerapkan model pembelajaran Circuit Learning yang mana peserta didik ditugaskan berkelompok untuk memahami materi dan soal yang diberikan sehingga peserta didik mampu perkelompok untuk menjelaskan kembali materi dan soal secara bersama didepan kelas sedangkan untuk kelas kontrol menggunakan model scientific, dimana model ini sudah biasa dilakukan disekolah SMA Kartika I-5 Padang.

Penilaian belajar menggunakan dari aspek kognitif dan afektif, aspek kognitif diamati berupa kegiatan peserta didik saat proses belajar berlangsung diatas pada ranah kognitif kegiatan belajar dengan model Circuit Learning di kelas eksperimen memiliki pengaruh pada hasil belajar, sedangkan untuk ranah afektifnya grafik diatas adanya peningkatan yang baik setiap pertemuan pada kelas eksperimen sehingga berpengaruh terhadap hasil belajar fisika peserta didik, lokal percobaan penelitian dari indikator pertama sampai indikator ketiga nilai lebih unggul eksperimen dibandingkan kontrol. 


\section{KESIMPULAN}

Berdasarkan penelitian yang telah dilaksanakan pada kelas eksperimen dan kontrol di SMA kartika I-5 Padang bahwa dalam pengolahan data yang telah dilakukan didapatkan pada reliabelitas soal $r_{11}=0,836$ dan $r_{\text {tabel }}=0,42$ reliabel dan terdistribusi normal tetapi tidak homogen. Penelitian yang dilakukan, didapatkan rata-rata ranah kognitif kelas eksperimen 73,53 kelas kontrol 52,8 . Ranah afektif didapatkan kelas eksperimen 55,99 kelas kontrol 50,88. Hasil uji hipotesis menggunakan uji dua pihak didapatkan hasil belajar $t_{\text {hitung }}=-7,25$ dan $t_{\text {tabel }}=2,04$ yang mana hipotesis penelitian diterima. Dapat disimpulkan terdapatnya pengaruh model belajar circuit learning diserti LKPD terhadap hasil belajar fisika peserta didik kelas XI MIPA SMA Kartika I5 Padang dari pada menggunakan pendekatan saintifik.

\section{DAFTAR PUSTAKA}

Arikunto, S. (2014 : 239). Prosedur Penelitian Suatu Pendekatan Praktik. Jakarta : PT. Rineka Cipta.

Huda, M. (2017 : 311). Cooperatif Learning Metode, Teknik, Struktur dan Model Penerapan. Yogyakarta : Pustaka Pelajar.

Karwono \& Mularsih, H. (2017 : 13). Belajar dan Pembelajaran Serta Pemanfaatan Sumber Belajar. Depok : PT Grafindo Persada.

Khairani, M. (2017 : 5). Psikologi Belajar. Yogyakarta: Aswaja Pressindo.

Ramadhani, F (2018). Penerapan Model Pembelajaran Circuit Learning Terhadap Kemampuan Komunikasi Matematis Siswa Kelas X SMA N 1 Pasir Penyu.

Shoimin, A. (2016). Model Pembelajaran Inovatif dalam Kurikulum 2013. Yogyakarta : Ar-Ruzz Media.

Sudjana. (2005 : 239). Metode Statistik. Bandung: Tarsito.

Trianto. (2009 : 62 ). Mendesain Model Pembelajaran InovatifProgresif : Konsep, Landasan, dan Implementasi pada Kurikulum Tingkat Satuan Pendidikan (KTSP). Jakarta: Kencana. 